\title{
"l'd be so much more comfortable posting anonymously": Identified versus anonymous participation in student discussion boards
}

\author{
Lynne D. Roberts and Camilla J. Rajah-Kanagasabai \\ Curtin University, Australia
}

\begin{abstract}
Academic staff members encourage university students to use online student discussion boards within learning management systems to ask and answer questions, share information and engage in discussion. We explore the impact of anonymity on student posting behaviour. An online survey was completed by 131 second year undergraduate psychology students $(91 \%$ response rate). Overall, students reported being significantly more likely to post to discussion boards when anonymous posting was enabled than when identified posting was required $(d=.49)$. Students who preferred to post anonymously were significantly less likely to post on discussion boards requiring identification than other students $\left(\eta^{2}=.27\right)$. The experimental manipulation of anonymous/identified postings using a simulated discussion board thread revealed no significant differences in the perceived credibility of authors of anonymous and identified messages, or in the likelihood of responding to these messages. A combination of individual level factors; including online privacy concern, self-consciousness and self-efficacy; were predictive of the likelihood of making identified postings $\left(R^{2}=.387\right)$, but only self-efficacy was a significant unique predictor of anonymous postings $\left(s r^{2}=.05\right)$. Educators can consider enabling anonymous postings and providing training to increase student self-efficacy as ways of increasing student engagement through decreasing concerns about self-presentation online.
\end{abstract}

\section{Introduction}

Recent estimates suggest that three-quarters of university students access learning management systems such as Blackboard and WebCT (Dahlstrom, de Boor, Grunwald, \& Vockley, 2011). Online student discussion boards embedded within learning management systems facilitate asynchronous threaded discussions. Increasingly, academic staff are encouraging university students to use these online student discussion boards to ask and answer questions, share information and engage in discussion (Weisskirch \& Milburn, 2003), reducing the need for faculty to engage in one-on-one communication with individual students (Warren, 2008). In this paper we explore the use of student discussion boards by Australian undergraduate psychology students, specifically examining the impact of anonymity on the perceived credibility of authors and messages, and the individual-level factors that predict student use of discussion boards. Given the increasing focus on teaching online, an understanding of the effects of anonymity/ identification in online discussion boards has important pedagogical implications.

Student discussion boards provide opportunities for academic and personal engagement. The process of writing posts for student discussion boards can encourage reflection (Hammond, 2005; Pena-Shaff, Altman, \& Stephenson, 2005; Redmon \& Burger, 2004; Warren, 2008), although individual postings may vary from shallow to deep (Warren, 2008). Online discussion boards increase perceptions of control over the discussion, with students able to take time to structure their ideas (Pena-Shaff et al., 2005). Participation rates in student discussion boards vary widely across courses, depending upon structural factors such as the guidelines provided and instructor presence (Dennen, 2005; Hew, Cheung, \& Ng, 2010). When students are required to post, the number of postings is usually only slightly higher than the number of required postings (Pena-Shaff \& Nicholls, 2004; Pena-Shaff et al., 2005). When posting is optional there can be wide variation in the frequency of postings by course members, with some dominating, and others not posting at all (Patel \& Aghayere, 2006; Van Soest, Canon, \& Grant, 2000). Students are more likely to respond to messages when they know the author, think the posting is interesting, or disagree with a posting (Pena-Shaff et al., 2005). Active discussion boards with high levels of student interaction can result in increased sense of community (Dawson, 2006) and student satisfaction (Ravenna, Foster, \& Bishop, 2012). However, even students who do not post to discussion boards may benefit from them. Beaudoin (2002) discussed the concept of the invisible learner, who, while not posting to student discussion boards, may be actively engaged in reading postings by others. 
Most learning management systems can be set to allow identified postings, anonymous postings or both, with course coordinators controlling these settings. Students report that using student discussion boards anonymously is associated with perceptions of perceived psychological safety (Van Soest et al., 2000; Yu \& Liu, 2009), being able to express feelings and views on sensitive issues without being identified, more open communication, (Van Soest et al., 2000), increased honesty and feelings of connectedness (Bertera \& Littlefield, 2003). Anonymity may be used to ask questions, clarify expectations and provide negative feedback (Freeman \& Bamford, 2004). In addition, anonymity can result in increased participation, including from students who are not active communicators in the classroom (Freeman \& Bamford, 2004; Miyazoe \& Anderson, 2011; Sullivan, 2002). Despite the posited advantages, enabling anonymous postings on student discussion boards has also been associated with a range of negative behaviours including negative, disruptive postings (Chester \& Gwynne, 1998; Van Soest et al., 2000) and attacks on other students (Anderson \& Simpson, 2008). Not all students support the use of anonymous postings (Johnson, 2010), with some fearing the negative postings that anonymity may allow.

\section{Credibility of authors and postings}

One way in which anonymity may affect posting behaviour is through altering perceptions of the credibility of postings and authors. Little is known about the effect of anonymity on the perceived credibility of postings and authors within the context of student discussion boards. Anonymity has been posited to help students focus on the content of posts, rather than the author (Miyazoe \& Anderson, 2011) in addition to increasing perceptions that a student's own posts will be judged on content.

Within the wider literature on the impact of anonymity, Metzger (2007) outlined more than 20 factors that have been suggested to influence the credibility assessments of online information ranging from author characteristics and argument plausibility through to typographical errors. Perceived credibility is affected by both consumer and source characteristics (Chesney \& Su, 2010) and can relate to both the messenger and the message. Findings in relation to the effect of anonymity on perceived credibility have been mixed. Perceived credibility may be reduced for anonymous information and anonymous authors (Rains 2007a), with anonymous postings increasing the difficulty in judging the reliability of information (Chen, Chen, Lo, \& Yang, 2008). However some research has reported no differences in the perceived credibility of identified and anonymous bloggers and blogs (Chesney \& $\mathrm{Su}, 2010$ ) or information on websites (Rains, 2007b). If the perceived credibility of authors and postings is reduced when postings are anonymous, this may reduce the usefulness of anonymous student discussion boards, with students doubting the validity of information posted.

\section{Predicting posting behaviour on student discussion boards}

Previous research findings on the potential academic and social benefits of active engagement in student discussion boards combined with the reported wide variation in the posting behaviour of students highlight the importance of understanding the predictors of student posting behaviour, in order to create an environment within student discussion boards that is conducive to maximising student participation. A range of individual and situational factors have been suggested to influence posting behaviour, either on student discussion boards or more broadly on social networking sites. Each of these is reviewed below and their possible relationships to posting behaviour on anonymous and identified discussion boards hypothesised.

\section{Online privacy concern}

One individual factor that may affect comfort with posting on student discussion boards is concern about privacy when interacting online. While research to date has focussed on online privacy concern in relation to interaction on social networking sites such as Facebook (e.g., Fogel \& Nehmad, 2009), key findings are that female undergraduate students have higher levels of online privacy concern, place higher importance on protecting identify information online and are more concerned with the consequences of sharing identity information than male undergraduate students (Fogel \& Nehmad 2009). Higher levels of online privacy concern are associated with greater general caution in relation to protecting privacy online (Buchanan, Paine, Joinson, \& Reips, 2007). Online users may allay privacy concern issues through the use of anonymity (Chen et al., 2008). It is hypothesised there will be a negative relationship between online privacy concern and the likelihood of posting in identified student discussion boards. 


\section{Self-consciousness}

Self-consciousness is a personality trait defined as "the consistent tendency of persons to direct attention inward or outward" (Fenigstein, Scheier, \& Buss, 1975, p. 522). Self-consciousness may be private, with a strong internal focus on the self, or public, based on the awareness of the self as perceived by others (Fenigstein et al., 1975). Within virtual environments, individuals high in public-self-consciousness may focus on how their messages are being perceived by others (Zhang, Fang, Wei, \& Chen, 2010). It is hypothesised that there will be a negative relationship between self-consciousness and the likelihood of posting in identified student discussion boards.

Fear of negative evaluation

Individuals vary in the degree of fear they experience about the potential to be negatively evaluated (Leary, 1983). Fear of negative evaluation may result in an individual avoiding situations where they may be unfavourably evaluated (Leary, 1983). Some students fear their postings will be negatively evaluated and they will be seen as ignorant (Pena-Shaff et al., 2005). Students participating in online learning forums and blogs who expressed preference for anonymity/pseudonymity online partially explained this preference in terms of "freeing themselves from others' eyes and evaluations" and "from making mistakes in front of others" (Miyazoe \& Anderson, 2011, p. 181). It is hypothesised there will be a negative relationship between fear of negative evaluation and likelihood of posting in identified student discussion boards.

Trust

Trust in virtual communities has been defined as "virtual community members' general belief that the community can be trusted and relied upon to share and exchange knowledge" (Zhang et al., 2010, p. 428). Previous research has supported a positive relationship between trust and knowledge sharing in virtual environments (Chiu, Hsu, \& Wang, 2006; Hsu, Ju, Yen, \& Chang, 2007) with trust hypothesised to be an antecedent of perceived psychological safety (Zhang et al., 2010). It is hypothesised that there will be a positive relationship between trust and likelihood of posting in both identified and anonymous student discussion boards.

\section{Perceived psychological safety}

Perceived psychological safety represents a state, rather than a trait, as it is context-dependent (Zhang et al., 2010). In the context of virtual communities, Zhang and colleagues define perceived psychological safety as "one's emotional ability to express oneself in a virtual community without fear of negative consequences in relation to well-being, self-image, and status." (p. 427), predicting that personal expression will be greater in virtual environments where individuals feel psychologically safe. It is hypothesised that there will be a positive relationship between perceived psychological safety and likelihood of posting in both identified and anonymous student discussion boards.

\section{Knowledge/self-efficacy}

Individuals' perceptions of their knowledge/self-efficacy in sharing knowledge within virtual environments may also be predictive of posting behaviour in student discussion boards. In professional virtual communities knowledge sharing self-efficacy has been positively related to knowledge sharing behaviour ( $r=.45$; Hsu et al., 2007). Similarly, knowledge sharing self-efficacy has been significantly associated with intention to share knowledge $(\mathrm{r}=.43$; Zhang et al., 2010). It is hypothesised that there will be a positive relationship between self-efficacy and likelihood of posting in both identified and anonymous student discussion boards.

In summary, this review of previous research suggests that online privacy concern, self-consciousness and fear of negative evaluation may be negatively correlated with identified postings on student discussion boards, while trust, perceived psychological safety and knowledge/self-efficacy may be positively related with both identified and anonymous postings on student discussion boards.

\section{Research Aims}

This research had three aims. The first aim was to explore students' preference for identified versus anonymous postings on student discussion boards. It was hypothesised that:

H1: More students would report preferring to post anonymously than identified. 
H2: Students will be more likely to post when a discussion forum allows anonymous posting.

H3: Students that prefer to be identified when posting to online discussion boards will be more likely to post to student discussion boards than students that prefer to be anonymous.

The second aim of this research was to experimentally gauge the effect of identification and anonymity on the perceived credibility of the sender and the likelihood of responding to messages. Students were randomly assigned to rate each message of either an anonymous or identified simulated student discussion thread. The thread messages differed only in whether each posting had the name of sender or has been posted anonymously. It was hypothesised that:

H4: Students in the identified condition will rate the senders of messages as more credible than students in the anonymous condition.

H5: Across conditions, perceptions of sender credibility will be positively correlated with likelihood of responding.

H6: Students in the identified condition will report a greater likelihood of responding to measures than students in the anonymous condition.

The third aim of the research was to examine a range of variables indicated by previous literature as possible predictors of the self-reported likelihood of posting on (a) anonymous and (b) identified student discussion boards. It was hypothesised that:

H7: Online privacy, self-consciousness, fear of negative evaluation, trust, perceived psychological safety and knowledge/self-efficacy will each account for significant unique variance in the self-reported likelihood of posting to identified student discussion boards.

H8: Trust, perceived psychological safety and knowledge/self-efficacy will each account for significant unique variance in the self-reported likelihood of posting to anonymous student discussion boards.

To our knowledge, this will be the first study to utilise an experimental design to randomly assign students to rate the perceived credibility of message senders and the likelihood of replying to anonymous and identified postings using simulated discussion threads with high ecological validity. As such, the findings will make a valuable contribution to the literature on the effect of anonymity within online academic settings.

\section{Method}

\section{Research Design}

A cross-sectional correlational design with an experimental component involving random allocation to conditions (identified versus anonymous) was used for this research. Students completed self-report measures of personality and behaviour in an online survey. Self-report measures are the most commonly used and widely accepted method of assessing personality (McDonald, 2008), retain their equivalence across online and offline administration (Roberts, 2006) and are appropriate for this study where the emphasis is on students' perceptions of their own personality and behaviour.

\section{Participants}

In total, 131 second year undergraduate psychology students ( $72.5 \%$ female, $27.5 \%$ male) from one Australian university participated in this study. Participating students ranged from 17 to 51 years $(M=$ $21.54, S D=5.72)$ with the majority studying full time $(94.7 \%)$. Students were recruited though an undergraduate psychology participant pool and received research credits for participating. There were 144 students enrolled in the participant pool, with the 131 participants providing a response rate of $91 \%$. Participation was voluntary and students could elect to take part in other studies or complete alternative written activities. 


\section{Measures}

An online survey comprising the following measures was created and hosted by Qualtrics.com.

\section{Likelihood of responding}

Participants were exposed, one message at a time, to an eleven message mock discussion thread. Each message was designed by the authors (an academic and a student who both regularly use student discussion boards) to explicitly match one of the 11 knowledge construction categories identified by Pena-Shaff and Nicholls (2004) in their content analysis of the most common patterns of discourse in online student discussion boards (Table 1). To enhance ecological validity, messages contained spelling and grammatical errors and abbreviations, designed to reflect the content of actual student postings, and each new message was displayed with the messages preceding it for ecological validity. Following the display of each new message, participants were asked to examine each message and rate the likelihood of responding to the message using a 5 point scale from 1 (Not very likely) to 5 (Very likely). The mock discussion thread, questions and response formats were pilot-tested with students prior to inclusion in the survey. The measure has high internal consistency $(\alpha=.89)$.

Table 1

Mapping of items onto knowledge construction categories

\begin{tabular}{|c|c|}
\hline Category & Item \\
\hline Question & $\begin{array}{l}\text { Just a quick question, when refferring to quantitative research, does that just } \\
\text { mean using only questionnaires? }\end{array}$ \\
\hline Reply & $\begin{array}{l}\text { I've done an assignment where we gathered data from the questionaires we } \\
\text { handed out to people. }\end{array}$ \\
\hline Clarification & $\begin{array}{l}\text { When you look at both qualitative and quantitative research, there's benefits to } \\
\text { both, with quantitative, using questionnaires and surveys mean that the data is } \\
\text { quicker to analyse. Whereas qualitative research is good, because of the depth of } \\
\text { answers from just one interview is really valuable, only doing the transcribing is } \\
\text { the annoying part!!! haha }\end{array}$ \\
\hline Interpretation & $\begin{array}{l}\text { It's almost like, you could say, that people who prefer quantitative research, like } \\
\text { math and stats and that sort of thing }\end{array}$ \\
\hline Conflict & $\begin{array}{l}\text { That's a bit far-fetched, just bvecause you may like maths, can no way suggest } \\
\text { that you will only like quantitative research. it all depends on what type of } \\
\text { results you want to work with. }\end{array}$ \\
\hline Assertion & $\begin{array}{l}\text { Like i said before, each research method alone is pretty valuable in it's own way, } \\
\text { nd extremely effective, but in order to the best result, you'd probs want to look at } \\
\text { mixed methods research. }\end{array}$ \\
\hline Consensus building & $\begin{array}{l}\text { Well maybe, if you think about it, the reason why mixed methods research is so } \\
\text { esteemed, is because it mixes the best of both worlds, so you end up with a more } \\
\text { complex data set. }\end{array}$ \\
\hline Judgment & $\begin{array}{l}i \text { agree that mixed methods research is the most effective type of research } \\
\text { metod, but what's the point of having a complex data set, if using just qualitative } \\
\text { or quantitative research is sufficient? }\end{array}$ \\
\hline Other & $\begin{array}{l}\text { that's pretty interesting, btw did anyone see that major lightning storm the other } \\
\text { day? i got some way cool pics }\end{array}$ \\
\hline Reflection & $\begin{array}{l}\text { It's my opinion that mixed methods research isn't used as often. i think in a lot of } \\
\text { ways its overlooked because of the time and effort needed to get a result. }\end{array}$ \\
\hline Support & I feel the same way. \\
\hline
\end{tabular}

Perceived credibility

After viewing each message participants were also asked to indicate their impression of the person who posted the message. Five items adapted from Chesney and Su's (2010) measure of perceived credibility of bloggers were used to assess students perceptions of the credibility of the message sender using a 7 point Likert scale from 1 (Strongly disagree) to 7 (Strongly agree). An example item is "I perceive the writer to be credible". All measures had high internal reliability ( $\alpha=.84$ to .96$)$. 


\section{Preferred mode of interaction}

A measure was developed consisting of four items that asked respondents their preferences for anonymity or identification when using student discussion boards. This measure was inspired by the questions asked by $\mathrm{Yu}$ and Liu (2009) about mode preferences when students use online contexts for questionconstruction and peer-assessment. An example item is "When posting questions on online student discussion boards, do you prefer to post". All questions have as response options using your real name, anonymously, no preference, or I don't post under any circumstances. Each participant was assigned to one of these four categories or a mixed category based on their responses.

\section{Likelihood of posting on anonymous and identified discussion boards}

Four items asked about the likelihood of posting questions, posting answers, starting discussion threads and posting links on a) anonymous student discussion boards and b) student discussion boards requiring identification. Two items were adapted from Patel and Aghayere (2006). Students responded on a scale ranging from 1 (Not very likely) to 5 (Very likely).

Online privacy concern

Online privacy concern was measured using the six highest loading items from Buchanan et al.'s (2007) Online Privacy Concern Scale. An example items is "Are you concerned about people online not being who they say they are?" Students respond on a 5 point Likert scale ranging from 1 (Not at all) to 5 (Very much).

\section{Self-consciousness}

To assess student's self- consciousness on student discussion boards, the three items from Shepers, de Jong, Wetzels, and de Ruyter (2008) were adapted by changing "groups" to "online student discussion boards". An example item is "I worry about how others perceive me on online student discussion boards". Students responded on a 7 point Likert scale ranging from 1 (Strongly disagree) to 7 (Strongly agree).

Fear of negative evaluation.

Twelve items were adapted from Leary (1983) in order to measure fear of negative evaluation on online student discussion boards. An example item is "I am afraid that others will not approve of my comments on online student discussion boards". Responses were measured on a 5 point Likert scale ranging from 1 (not at all characteristic of me) to 5 (extremely characteristic of me).

Trust

Three items, adapted from Zhang et al. (2010), measured trust in online student discussion boards. An example item is "I have trust in online discussion boards". Items were measured on a 7 point Likert scale ranging from 1 (Strongly disagree) to 7 (Strongly agree).

\section{Perceived psychological safety}

Three items adapted from Zhang et al. (2010) were used to examine perceived psychological safety on student discussion boards. An example item is "I am afraid to express my opinions on online student discussion boards". Students responded on a 5 point Likert scale ranging from 1 (Strongly disagree) to 5 (Strongly agree).

\section{Knowledge/self-efficacy}

Four items were adapted from Kankalli, Tan, and Wei (2005) to evaluate how confident and competent students felt on discussion boards. An example item is "I have confidence in my ability to provide knowledge that others on online student discussion boards consider valuable". Responses were measured on a 7 point Likert scale ranging from 1 (Strongly disagree) to 7 (Strongly agree).

\section{Procedure}

Participants were recruited through the second year undergraduate psychology participant pool of an Australian university over a thirteen week period from March to May 2012. Interested students were directed to an online information sheet and upon consenting to participate in the study were randomly assigned to one of two versions of the questionnaire hosted on Qualtrics.com. One version featured a discussion thread where all postings were anonymous, while on the second version all postings were identified. Each student was exposed to one discussion thread (anonymous or identified) only, and 
answered the Likelihood of Responding and Perceived Credibility measures in relation to this. All other measures were identical for all respondents. Upon submitting their survey responses, participants were assigned participation credits.

Data were downloaded into SPSS (v. 20) for analysis. A missing values analysis indicated $1.5 \%$ of data points on scales were missing. Little's MCAR test $\left(\chi^{2}(5641)=5801, p=.067\right)$ indicated that the missing data occurred completely at random. Missing values were replaced using mean substitution. Prior to hypothesis testing the factor structure and reliability of measures were assessed. Principal Axis Factoring supported the unidimensionality of each of the scale measures. Cronbach's alpha for each measure is reported in Table 5. There were no violations of assumptions for the statistical tests conducted.

\section{Results}

Student reported preferences for level of identification when posting are presented in Table 2. Across the four activities, approximately one quarter of respondents reported preferring posting anonymously, a quarter to a third of students reported preferring identified postings, approximately a third had no preference and up to $15 \%$ reported they wouldn't post under any circumstances. Posting links was the activity least associated with a preference for posting anonymously. H1, predicting that more students would prefer to post anonymously than identified, was not supported.

Table 2

Preferred level of identification when posting on student discussion boards $(N=131)$

\begin{tabular}{lllll}
\hline Activity & $\begin{array}{l}\text { Identified } \\
\%\end{array}$ & $\begin{array}{l}\text { Anonymous } \\
\%\end{array}$ & $\begin{array}{l}\text { No preference } \\
\%\end{array}$ & $\begin{array}{l}\text { Don't post } \\
\%\end{array}$ \\
\hline Posting questions & 29.8 & 26.7 & 35.1 & 8.4 \\
Answering questions & 25.2 & 24.4 & 35.1 & 15.3 \\
Starting discussion threads & 32.1 & 27.5 & 30.5 & 9.9 \\
Posting links & 33.6 & 19.1 & 32.1 & 15.3 \\
\hline
\end{tabular}

H2 predicted that students would report being more likely to post when a student discussion board allowed anonymous posting. A paired sample $t$-test indicated that students reported they were significantly more likely to post when anonymous posting was allowed $(M=3.26, S D=1.06)$ than when identified posting was required $(M=2.71, S D=1.19, t(123)=5.22, p<.001, d=.49)$. H2 was supported.

H3 predicted a higher likelihood of posting by students that prefer to be identified than those who prefer to be anonymous. To test this hypothesis two ANOVAs with Tukey post-hoc comparisons were conducted (Table 3). Students who prefer to be identified reported a higher likelihood of posting on discussion boards requiring identification $\left(F(2,121)=22.19, p<.001, \eta^{2}=.27\right)$, than students who preferred anonymous posting or had no preference. However, students who preferred to post anonymously did not significantly differ from those who preferred identification in the reported likelihood of posting on anonymous discussion boards, but reported a higher likelihood of posting than those students who had no preference in regard to identification, $\left(F(2,121)=3.80, p=.025, \eta^{2}=.06\right)$. This hypothesis was partially supported, with students that prefer to be identified more likely to post than other students on identified discussion boards only.

Table 3

Responding behaviour by identification preferences

\begin{tabular}{llll}
\hline & $\begin{array}{l}\text { Prefer } \\
\text { identification } \\
n=47\end{array}$ & $\begin{array}{l}\text { Prefer } \\
\text { anonymity } \\
n=40\end{array}$ & $\begin{array}{l}\text { No } \\
\text { preference } \\
n=37\end{array}$ \\
\cline { 2 - 4 } Responding Behaviour & Mean (SD) & Mean (SD) & Mean $(S D)$ \\
\hline Likelihood of responding (identified) & $3.35(1.12)^{*}$ & $1.88(.93)^{*}$ & $2.79(.98)^{*}$ \\
Likelihood of responding (anonymous) & $3.35(1.04)^{*}$ & $3.51(.89)$ & $2.89(1.15)^{*}$ \\
\hline
\end{tabular}

Note. ${ }^{*}$ Tukey HSD indicates conditions significantly differ $(p<.05)$ 
The second aim of this research was to experimentally gauge the effect of identification and anonymity on the perceived credibility of the sender and the likelihood of responding to messages. The experimental manipulation within the survey resulted in 68 students being randomly assigned to the identified postings condition and 63 to the anonymous postings condition. To test $\mathrm{H} 4$, that students would rate the senders of identified messages as more credible than the senders of anonymous messages, a between groups MANOVA was conducted with condition (identified/anonymous) as the independent variable and the perceived credibility of each of the 11 messages as the dependent variables (Table 4). The results indicate that there is no significant difference in the perceived credibility of anonymous and identified message senders across message types $\left(F(11,119)=0.48, p=.90\right.$ partial $\left.\eta^{2}=.044\right)$. This hypothesis was not supported.

Table 4

Perceived credibility of message sender for anonymous and identified messages and spearman rho correlation with likelihood of responding to message

\begin{tabular}{lllll}
\hline Type of Message & $\begin{array}{l}\text { Identified } \\
(n=68) \\
\text { Mean }(S D)\end{array}$ & rho & $\begin{array}{l}\text { Anonymous } \\
(n=63) \\
\text { Mean }(S D)\end{array}$ & rho \\
& & & & \\
\hline Question & $4.33(1.24)$ & .05 & $4.19(1.11)$ & .03 \\
Reply & $3.75(1.30)$ & .11 & $3.75(1.22)$ & .03 \\
Clarification & $4.75(1.43)$ & .12 & $4.83(1.23)$ & .25 \\
Interpretation & $3.18(1.42)$ & $.35^{* *}$ & $3.07(1.18)$ & .03 \\
Conflict & $4.64(1.14)$ & $.49 * *$ & $4.42(1.33)$ & $.47 * *$ \\
Assertion & $4.62(1.43)$ & .17 & $4.52(1.32)$ & .20 \\
Consensus building & $4.79(1.29)$ & $.40^{* *}$ & $4.72(1.22)$ & $.39^{* *}$ \\
Judgement & $4.69(1.14)$ & $.32^{* *}$ & $4.41(1.22)$ & $.46^{* *}$ \\
Other & $2.16(1.15)$ & .29 & $2.10(1.04)$ & .12 \\
Reflection & $4.95(0.85)$ & .18 & $4.67(1.02)$ & $.36^{* *}$ \\
Support & $3.49(1.27)$ & .02 & $3.43(1.05)$ & -.05 \\
\hline
\end{tabular}

Note. $* * p<.01$ (2-tailed)

To test H5, that students will be more likely to respond to messages if they perceive the writer to be credible, a non-parametric (Spearman's rho) correlation of perceived credibility and likelihood of responding was conducted for each message by condition (Table 4) using a more stringent alpha level of $p<.01$ to account for multiple tests. Significant medium size relationships were found across conditions for conflict, consensus building, and judgement messages, with significant relationships found for interpretation and reflection in the identified and anonymous conditions respectively. This hypothesis was partially supported.

To test H6, that students will be more likely to respond to identified messages than anonymous messages, an independent groups t-test was conducted. There was no significant difference in the likelihood of responding to messages in the identified $(M=2.02, S D=.77)$ and anonymous conditions $(M=1.88, S D=.73$, $t(129)=1.09, p=.277)$. This hypothesis was not supported.

The third aim of the research was to examine a range of possible individual level variables as predictors of the self-reported likelihood of posting anonymous and identified messages on student discussion boards. Descriptive statistics and correlations are presented in Table 5 and Table 6 respectively. Two multiple regression analyses were conducted with self-reported likelihood of anonymous posting and selfreported likelihood of identified posting as the criterion variables and all predictor variables entered in one step. The results are presented in Table 7. In combination, the predictor variables accounted for $38.7 \%$ of the variance in the likelihood of posting identified messages, $(F(6,124)=13.04, p<.001$, $\left.R^{2}=.387\right)$ and $11.7 \%$ of variance in posting anonymous messages, $\left(F(6,124)=2.751, p=.015 . R^{2}=.117\right)$. Online privacy concern, perceived psychological safety and self-efficacy were significant unique predictors of identified postings, partially supporting H7. Only self-efficacy was a significant predictor of anonymous postings, partially supporting $\mathrm{H} 8$. 
Table 5

Descriptive statistics for scales $(N=131)$

\begin{tabular}{llll}
\hline Scale & Mean $(S D)$ & Possible Range & Scale $\alpha$ \\
\hline 1. Likelihood of posting anonymously & $3.20(1.10)$ & 1 to 5 & .89 \\
2. Likelihood of posting identified & $2.63(1.21)$ & 1 to 5 & .92 \\
3. Online privacy concern & $3.35(1.00)$ & 1 to 5 & .92 \\
4. Self-consciousness & $4.34(1.56)$ & 1 to 7 & .86 \\
5. Perceived psychological safety & $3.46(0.88)$ & 1 to 5 & .73 \\
6. Trust & $4.65(0.98)$ & 1 to 7 & .84 \\
7. Knowledge/Self-efficacy & $3.82(1.18)$ & 1 to 7 & .82 \\
8. Fear of negative evaluation & $2.98(0.85)$ & 1 to 5 & .91 \\
\hline
\end{tabular}

Table 6

Correlations for measures included in the regression analyses $(N=131)$

\begin{tabular}{lllllllll}
\hline Scale & 1 & 2 & 3 & 4 & 5 & 6 & 7 & 8 \\
\hline 1. Likelihood of posting anonymously & 1.00 & $.47^{* *}$ & .06 & .03 & .07 & .15 & $.22^{*}$ & .00 \\
2. Likelihood of posting identified & & 1.00 & .16 & $-.42^{* *}$ & $.47^{* *}$ & $.24^{* *}$ & $.53^{* *}$ & $-.37^{* *}$ \\
3. Online privacy concern & & & 1.00 & $.27^{* *}$ & $-.22^{* *}$ & .00 & -.04 & $.26^{* *}$ \\
4. Self-consciousness & & & & 1.00 & $-.75^{* *}$ & $-.21^{*}$ & $-.57^{* *}$ & $.80^{* *}$ \\
5. Perceived psychological safety & & & & & 1.00 & $.21^{*}$ & $.61^{* *}$ & $-.74^{* *}$ \\
6. Trust & & & & & & 1.00 & $.19^{*}$ & $-.21^{*}$ \\
7. Knowledge/Self-efficacy & & & & & & & 1.00 & $-.57^{* *}$ \\
8. Fear of negative evaluation & & & & & & & & 1.00
\end{tabular}

Note. $* p<.05$ (2-tailed); $* * p .01$ (2-tailed)

Table 7

Regression coefficients and squared semi-partial correlations $\left(s r^{2}\right)$ for regression models predicting the likelihood of posting to identified and anonymous student discussion boards

\begin{tabular}{lcccccc}
\hline & \multicolumn{3}{c}{ Identified } & \multicolumn{3}{c}{ Anonymous } \\
Predictor & $B[95 \% \mathrm{CI}]$ & $\beta$ & $s r^{2}$ & $B[95 \% \mathrm{CI}]$ & $\beta$ & $s r^{2}$ \\
\hline Online privacy concern & $.30[.13, .48]^{* *}$ & .25 & .06 & $.13[-.06, .33]$ & .12 & .01 \\
Self-consciousness & $-.12[-.31, .08]$ & -.15 & .01 & $.14[-.08, .36]$ & .20 & .01 \\
Perceived psychological safety & $.34[.02, .66]^{*}$ & .25 & .02 & $.14[-.21, .49]$ & .11 & .00 \\
Trust & $.13[-.04, .31]$ & .11 & .01 & $.15[-.04, .34]$ & .13 & .02 \\
Knowledge/self-efficacy & $.33[.14, .52]^{* *}$ & .32 & .06 & $.27[.07, .48]^{* *}$ & .30 & .05 \\
Fear of negative evaluation & $.10[-.26, .45]$ & .07 & .00 & $.12[-.27, .51]$ & .09 & .00 \\
\hline Note. ${ }^{*} p<.05\left(\right.$ 2-tailed); ${ }^{* *} p<.01(2$-tailed) & & & & &
\end{tabular}




\section{Discussion}

The first aim of this research was to explore students' preferences for identified versus anonymous postings on student discussion boards. The results indicate wide variation in preferences, with only one quarter of students indicating they preferred to post anonymously (H1). Consistent with previous research (Miyazoe \& Anderson, 2011; Sullivan, 2002), overall students reported they are more likely to post when student discussion boards allow anonymous postings (medium size effect, H2). However, the explanation for this appears to lie in the finding that students who prefer to post anonymously do not differ from those who prefer to make identified postings in their likelihood of posting on anonymous discussion boards, but they do post significantly less on discussion boards requiring identification (H3). The effect size was large, suggesting one pedagogical implication is that enabling anonymous postings on student discussion boards may increase the engagement of those students who prefer anonymity. However, by doing so, educators may be privileging one group (the quarter of students who prefer anonymous posting) over other groups who prefer identified discussion boards.

Any change to allow anonymous postings needs to be done with care, given reports of previous instances of negative behaviours in anonymous student discussion boards (Anderson \& Simpson, 2008; Chester \& Gwynne, 1998; Van Soest et al., 2000). To reduce the incidence of negative behaviours clear behavioural expectations need to be set, with students advised that while postings are anonymous to other student users, the sender can be easily traced by the unit coordinator where ground rules for acceptable use are breached. Further, consideration needs to be given to the increased administrative load for academic staff associated with both the increased number of postings and increased monitoring required, particularly in the early stages.

The second aim of this research was to experimentally gauge the effect of identification and anonymity on the perceived credibility of the sender and the likelihood of responding to messages. No significant differences were found in the perceived credibility of anonymous and identified message senders across all message types (H4), supporting previous research that has found no differences within other online settings (Chesney \& Su, 2010; Rains, 2007b). Further, no significant difference was found in the likelihood of responding to identified and anonymous messages (H6). While there were some medium positive correlations found between the perceived credibility of the sender and likelihood of responding to a message, this finding was not consistent across all messages. The findings that anonymity does not impact on either perceptions of the credibility of the sender or on the likelihood of responding to a message provide support for considering enabling anonymous postings on student discussion boards.

The third aim of the research was to examine a range of predictors of the likelihood of posting on anonymous and identified student discussion boards. Based on the correlation matrix and regression analyses it is clear that a range of individual level variables affect the likelihood of posting to student discussion boards requiring identification. Consistent with previous research (Chiu, et al., 2006; Hsu, et al., 2007; Zhang et al., 2010), psychological safety, trust and self-efficacy were each associated with a greater likelihood of posting in the regression analysis. Also consistent with previous research (Miyazoe \& Anderson, 2011, Zhang et al., 2010) self-consciousness and fear of negative evaluation were each individually negatively associated with likelihood of posting. Inspection of the correlation matrix indicates that perceived psychological safety, self-consciousness and fear of negative evaluation were highly correlated, suggesting they are measuring highly related concepts. This may explain why selfconsciousness and fear of negative evaluation, while individually significantly associated with posting on identified discussion boards, did not account for significant unique variance in the regression analysis.

When the requirement for identification is removed, only knowledge/self-efficacy remains related to the likelihood of posting on student discussion boards. These results are consistent with previous research findings indicating that anonymous discussion boards are associated with increased perceived psychological safety (Van Soest et al., 2000; Yu \& Liu, 2009).

These results suggest that enabling anonymous postings on discussion boards may increase student engagement through providing a psychologically safe teaching environment that reduces the impact of self-consciousness and fear of negative evaluation on posting behaviour. If enabling anonymous postings is not an option for a particular discussion board, the results suggest alternative strategies to increase student engagement may be to provide training in the use of student discussion boards to increase self- 
efficacy, and to actively work to provide positive environment identified discussion boards that are perceived by students as psychologically safe.

While the results of this study increase our understanding of the impact of anonymity on student posting behaviour, the findings need to be viewed in light of the limitations of the study. One limitation of this research is the reliance on psychology students in one year from one university. However, offsetting this is the high response rate, which provides confidence that we have captured the variance across the student body in the individual differences measures of interest. Further research is required to test the generalizability of these findings across undergraduate and postgraduate years, and across courses with varying degrees of embedded online learning. A second limitation is the use of self-reports of posting behaviour, with a focus on the likelihood of posting, rather than direct measures of posting behaviours. While the use of direct measures was not feasible due to the experimental design component of this study, future research examining predictors of posting behaviours would benefit from using "count" measures.

A strength of this study was the experimental manipulation of anonymity in a created discussion thread that comprised messages across all categories of knowledge construction. Further research is required to experimentally manipulate anonymity in actual student discussion boards to measure posting behaviour. While it may not be ethically defensible or feasible to randomly assign students to discussion boards allowing identified and anonymous postings, it may be possible to randomly assign same year units within a year group to identified and anonymous discussion boards, or to alternate between identified and anonymous discussion boards on a semester basis. Research is also needed to further assess the efficacy of training in discussion board etiquette.

In summary, our findings provide support for considering enabling anonymous postings on discussion boards as a means of increasing student engagement through providing a "safe" teaching environment that reduces the impact of self-consciousness and fear of negative evaluation on posting behaviour. However, before such a strategy is implemented procedures need to be put in place to ensure that allowing anonymous postings does not result in increased negative behaviours. Alternately, student engagement may be increased through providing training in discussion board use to improve student self-efficacy.

\section{Acknowledgements}

This research was funded by a summer research scholarship awarded to Lynne D. Roberts and Camilla J. Rajah-Kanagasabai from PsyLIFE (PSY-SSS-2011-04).

\section{References}

Anderson, B., \& Simpson, M. (2008). Acting with integrity online: Some questions for educators. In Hello! Where are you in the landscape of educational technology? Proceedings ascilite 2008 Melbourne. Retrieved from http://www.ascilite.org.au/conferences/melbourne08/procs/anderson.pdf.

Beaudoin, M. F. (2002). Learning or lurking? Tracking the "invisible" online student. The Internet and Higher Education, 5(2), 147-155. doi:10.1016/S1096-7516(02)00086-6

Bertera, E. M., \& Littlefield, M. B. (2003). Evaluation of electronic discussion forums in social work diversity education: A comparison of anonymous and identified participation. Journal of Technology in Human Services, 21(4), 53-71. doi:10.1300/J017v21n04_04

Buchanan, T., Paine, C., Joinson, A., \& Reips, U. (2007). Development of measures of online privacy concern and protection for use on the internet. Journal of the American Society for Information Science and Technology, 58(2), 157-165. doi:10.1002/asi.20459

Chen, H. G., Chen, C. C., Lo, L., \& Yang, S. C. (2008). Online privacy control via anonymity and pseudonym: Cross-cultural implications. Behaviour \& Information Technology, 27, 229-242. doi:10.1080/01449290601156817

Chesney, T., \& Su, D. K. S. (2010). The impact of anonymity on weblog credibility. International Journal of Human Computer Studies, 68, 710-718. doi:10.1016/j.ijhcs.2010.06.001 
Chester, A., \& Gwynne, G. (1998). Online teaching: Encouraging collaboration through anonymity. Journal of Computer-Mediated Communication, 4(2). doi:10.1111/j.1083-6101.1998.tb00096.x

Chiu, C.-M., Hsu, M.-H., \& Wang, E. T. G. (2006). Understanding knowledge sharing in virtual communities: An integration of social capital and social cognitive theories. Decision Support Systems, 42, 1872-1888. doi:10.1016/j.dss.2006.04.001

Dahlstrom, E., de Boor, T., Grunwald, P., \& Vockley, M. (2011).The ECAR national study of undergraduate students and information technology, 2011. Boulder, CO: EDUCAUSE Center for Applied Research.

Dawson, S. (2006). Online forum discussion interactions as an indicator of student community. Australasian Journal of Educational Technology, 22(4), 495-510. Retrieved from http://www.ascilite.org.au/ajet/ajet22/dawson.html

Dennen, V. P. (2005). From message posting to learning dialogues: Factors affecting learner participation in asynchronous discussion. Distance Education, 26, 127-148. doi:10.1080/01587910500081376

Fenigstein, A., Scheier, M. F., \& Buss, A. H. (1975). Public and private self-consciousness: Assessment and theory. Journal of Consulting and Clinical Psychology, 43, 522-527. doi:10.1037/h0076760

Fogel, J., \& Nehmad, E. (2009). Internet social network communities: Risk taking, trust and privacy concerns. Computers in Human Behavior, 25, 153-160. doi:10.1016/j.chb.2008.08.006

Freeman, M., \& Bamford, A. (2004). Student choice of anonymity for learner identity in online learning discussion forums. International Journal on ELearning, 3(3), 45-53.

Hammond, M. (2005). A review of recent papers on online discussion in teaching and learning in higher education. Journal of Asynchronous Learning, 9(3), 9-23. Retrieved from http://old.sloanconsortium.org/jaln/pdfs/v9n3_hammond.pdf

Hew, K. F., Cheung, W. S., \& Ng, C. S. L. (2008). Student contribution in asynchronous online discussion: A review of the research and empirical exploration. Instructional Science, 38, 571-606.

Hsu, M. H., Ju, T. L., Yen, C. H., \& Chang, C. M. (2007). Knowledge sharing behavior in virtual communities: The relationship between trust, self-efficacy, and outcome expectations. International Journal of Human-Computer Studies, 65(2), 153-169. doi:10.1016/j.ijhcs.2006.09.003

Johnson, M. (2010). Anonymity in online discussion forums - does it promote connections? In L. Dirckinck-Holmfeld, V. Hodgson, C. Jones, M. de Laat, D. McConnell, \& T. Ryberg (Eds.), Proceedings of the 7th International Conference on Networked Learning 2010 (pp. 198-206).

Kankalli, A., Tan, B. C. Y., \& Wei, K. (2005). Contributing knowledge to electronic knowledge repositories: An empirical investigation. MIS Quarterly, 29(1), 113-143.

Leary, M. R. (1983). A brief version of the fear of negative evaluation scale. Personality and Social Psychology Bulletin, 9, 371-375. doi:10.1177/0146167283093007

McDonald, J. D. (2008). Measuring personality constructs: The advantages and disadvantages of selfreports, informant reports and behavioural assessments. Enquire, 1(1), 1-18.

Metzger, M. J. (2007). Making sense of credibility on the web: Models for evaluating online information and recommendations for future research. Journal of the American Society for Information Science and Technology, 58, 2078-2091. doi:10.1002/asi.20672

Miyazoe, T., \& Anderson, T. (2011). Anonymity in blended learning: Who would you like to be? Educational Technology \& Society, 14(2), 175-187. 
Patel, J., \& Aghayere, A. (2006). Student' perspective on the impact of a web-based discussion forum on student learning. Paper presented at 36th ASEE/IEEE Frontiers in Education Conference.

Pena-Shaff, J., Altman, W., \& Stephenson, H. (2005). Asynchronous online discussions as a tool for learning: Students' attitudes, expectations, and perceptions. Journal of Interactive Learning Research, $16,409-430$.

Pena-Shaff, J. B., \& Nicholls, C. (2004). Analysing student interactions and meaning construction in computer bulletin board discussions. Computers \& Education, 42, 243-265. doi:10.1016/j.compedu.2003.08.003

Rains, S. A. (2007a). The anonymity effect: The influence of anonymity on perceptions of sources and information on health websites. Journal of Applied Communication Research, 35(2), 197-214. doi:10.1080/00909880701262666

Rains, S. A. (2007b). The impact of anonymity on perceptions of source credibility and influence in computer-mediated group communication. Communication Research, 34(1), 100-125. doi:10.1177/0093650206296084

Ravenna, G., Foster, C., \& Bishop, C. (2012). Increasing student interaction online: A review of the literature. Journal of Technology and Teacher Education, 20(2), 177-203.

Redmon, R., \& Burger, M. (2004). Web CT discussion forums: Asynchronous group reflection of the student teaching experience. Curriculum and Teaching Dialogue, 6(2), 157-166.

Roberts, L. D. (2006). Equivalence of electronic and offline measures. In R. A. Reynolds, R. Woods, \& J. D. Baker (Eds.), Handbook of research on electronic surveys and measurements (pp. 96-102). Hershey, PA: Idea Group Inc.

Shepers, J., de Jong, A., Wetzels, M., \& de Ruyter, K. (2008). Psychological safety and social support in groupware adoption: A multi-level assessment in education. Computers \& Education, 51, 757-775. doi:10.1016/j.compedu.2007.08.001

Sullivan, P. (2002). "It's easier to be yourself when you are invisible": Female college students discuss their online classroom experiences. Innovative Higher Education, 27(2), 129-144. doi:10.1023/A:1021109410893

Van Soest, D., Canon, R., \& Grant, D. (2000). Using an interactive website to educate about cultural diversity and societal oppression. Journal of Social Work Education, 36, 463- 479.

Warren, C. M. J. (2008, February). The use of online asynchronous discussion forums in the development of deep learning among postgraduate real estate students. Paper presented at CIB International Conference on Building Education and Research. Sri Lanka.

Weisskirch, R. S., \& Milburn, S. S. (2003). Virtual discussion: Understanding college students' electronic bulletin board use. Internet and Higher Education, 6, 215-225. doi:10.1016/S1096-7516(03)00042-3

Yu, F., \& Liu, Y. (2009). Creating a psychologically safe online space for a student- generated questions learning activity via different identity revelation modes. British Journal of Educational Technology, 40, 1109-1123.

Zhang, Y., Fang, Y., Wei, K., \& Chen, H. (2010). Exploring the role of psychological safety in promoting the intention to continue sharing knowledge in virtual communities. International Journal of Information Management, 30, 425-436. doi:10.1016/j.ijinfomgt.2010.02.003 
Corresponding author: Lynne Roberts, Lynne.Roberts@curtin.edu.au

Australasian Journal of Educational Technology (C) 2013.

Please cite as: Roberts, L. D., \& Rajah-Kanagasabai, C. J. (2013). "I'd be so much more comfortable posting anonymously": Identified versus anonymous participation in student discussion boards. Australasian Journal of Educational Technology, 29(5), 612-625. 